\title{
A Unique Methodology For Implementing High School Capstone Experiences Through Teacher Professional Development
}

\author{
Jessica Chin, Northeastern University, USA \\ Abe Zeid, Northeastern University, USA \\ Claire Duggan, Northeastern University, USA \\ Sagar Kamarthi, Northeastern University, USA
}

\begin{abstract}
Innovators and abstract thinkers - students who question why are going to be the future of engineering, of science and cures for diseases. Rarely do students ask where and how innovation is created. Students, particularly post-secondary students have lost their curiosity and they have lost their ability to question. Why? Because the relationship between theory and application has been removed from our high schools. Although the term "STEM" is generally used, students do not appear to understand the importance of core STEM principles such as Newton's $2^{\text {nd }}$ law and therefore do not understand the influence these basic algorithms have in daily life. In recent decades, high school education has focused on quizzes and exams, state and national standardize testing and SATs. More emphasis is placed on performing well on these exams, focusing on memorization and test taking rather than on thorough comprehension. The question is, "how do you translate theory to application in the high school classroom?" Students' knowledge and engagement are only as good as their teachers. Educators need to be given the proper tools, resources, and knowledge. CAPSULE, a capstone-based experience provides tools, resources, and knowledge to enhance the teaching and learning involvement. CAPSULE teaches and promotes inquiry, exploration and application rather than just theory. The methodology engages and educates hands-on learning, teamwork and multiple solutions through the engineering design process (EDP). The theory behind innovation is the motivation for CAPSULE - to teach and engage teachers using $3 D$ modeling, EDP, and project-based learning to create a high school capstone experience. This paper presents a new approach of teaching STEM related courses to high school students. The methodology presented is on "training the trainer" to enable and empower teachers to master and utilize this new approach.
\end{abstract}

Keywords: STEM; Engineering; Capstone; EDP; CAPSULE; Technology Education; Product Design

\section{INTRODUCTION}

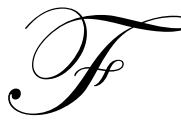

or many high school students, the knowledge and understanding of STEM (science, technology, engineering and mathematics) careers are unknown to them. This is not due to lack of desire or ability, but more lack of knowledge of possibilities of what type of careers they could have. Unfortunately, the focus of student achievement is on state and national test scores rather than content knowledge [1]. In the U.S. there is a great need for technical knowledge to address the challenges facing us in the $21^{\text {st }}$ century[2]. A goal for STEM education should be to understand how things work and improve upon them using current day technologies. The patent system was created to promote the sharing of ideas and reward inventors for their creativity. By publicly publishing inventions, it fosters further innovation and creativity compounded on what others had created. Similar to the patent system, the purpose of publishing, creating and designing is to improve upon products and methodologies that have become outdated [2]. Along their path, they will learn new technological tools like 3D modeling, industrial design and how aesthetics impact product sales as well as the design and development of a new product using principles from physics, geometry and chemistry. Students will understand 
how incremental innovations can and will result in a completed product; from sneakers to iPods ${ }^{\mathrm{TM}}$, everything involves principles from STEM subjects such as the how sneakers absorb energy versus the body. Students should also be able to recognize that STEM principles have its place in industries like end-use psychology, human factor design and user interfaces [3]. Engineering is directly related to problem solving and innovation, two primary issues facing every nation. Providing exposure to engineering is forcing a change in how K-12 education is delivered.

Most high school aged students who pursue engineering education are motivated by their prior knowledge, typically having a parent who is or has worked in the engineering field. That number however, is a small subset of the number of students graduating each year from U.S. high schools. As part of the ABET-accredited college engineering curriculum, the culminating capstone experience is a typical requirement of any undergraduate engineering program. The culmination of most engineering programs is one class; either a semester or yearlong course that is encompasses everything learned in four years of college. The collegiate capstone is where true application is realized and engineering students get to build something practical, something real, and something to solve a problem. Similarly, students only have the opportunity to experience the engineering design process (EDP) if they are enrolled in an undergraduate engineering program. However, what educators are learning and testing is that the EDP method can be applied to all STEM education and careers with slight modifications. Pedagogical research suggests that K-12 education has shifted from lecture-based memorization to project based, hands-on, reinforced learning $[3,4]$. This indicates that EDP offers the optimal platform that uses critical thinking and handson learning.

The criticality occurs with the realization that the U.S. postsecondary STEM degrees are rapidly falling behind our international counterparts which has raised numerous questions regarding our ability to keep pace with other nations [5]. In order to implement and encourage STEM careers, students need be motivated and interested in partaking in these STEM related courses. Pedagogical research implies that strictly lecture-based teaching methods are ineffective but most teachers lack the professional development and technological support to take advantage of new tools that engage students in a more effective manner [6].

This paper presents an innovative methodology, similar to the collegiate capstone experience, to implement the capstone experience at the high school level. It is theorized that high school students do not fully understand what an engineer does and why an individual would want a career in engineering. By introducing the capstone experience and EDP at the high school level, it provides students' insight into STEM careers and its future possibilities. EDP encourages critical thinking and open-ended problem solving. There is a vast difference between theory and reality and CAPSULE (CapStone Unique Learning Experience) bridges that gap.

\section{CAPSULE LEARNING METHOD}

Over the past thirty years, project based learning (PBL) and self-directed learning has gained increased awareness and support but still lacks significant evidence that supports how project based learning improves learning. Despite the lack of evidence, the adoption of PBL has extended into elementary, middle and high schools [7]. As part of the U.S. initiative to create more STEM related learning, our research supports the professional development of high school and community college teachers educating them on how to implement and engage students in more hands on, self directed learning. CAPSULE is a professional development course reinforces handson activities and addresses the fact that there are multiple ways to solve the same problem and examinations are not the only method to gaging students' knowledge and understanding. CAPSULE educates teaching faculty that project based learning and EDP can empower the students and learners to discover their own solutions, unconcerned if the final answer is "correct" [7]. By understanding multiple solutions to one problem, students can analyze why there is a best solution and why others may not meet the constraints as well.

CAPSULE is an NSF funded strategy project that was created to educate teachers on how to communicate to their students the importance and the usefulness of STEM courses on a daily basis. CAPSULE uses a top-down project based learning model [8] as an effective tool to connect with students on the importance of STEM and IT subjects. This method uses real-world problems to assist linking reality with STEM. For many students, it is the first true connection regarding the knowledge they are learning in the classroom and real-world tangibility. CAPSULE focuses on the engineering design process (EDP) delineated in the Massachusetts Framework [9]. 
EDP allows teachers and students alike to understand and realize the general steps included in product and solution innovation. There is significant emphasis on the understanding of EDP because it stresses iterative processing and reinforced learning. EDP is a non-restrictive process where students are not bounded by strict constraints. Figure 1 presents the EDP methodology that is used to educate teachers in this study. Students learn by doing and by analyzing and understanding real-world problems as they discover the relationship between STEM subjects and real-world applications [10]. Through the two-week professional development (PD) course, teachers experience capstone projects in conjunction with EDP steps similar to how it would be implemented in their own classrooms. They are given a problem and asked to solve it with colleagues using new technological tools that had been introduced earlier in the course. Teachers were asked to deliver prototypes, reports, presentations and poster sessions - very similar to what happens in the collegiate capstone experience.

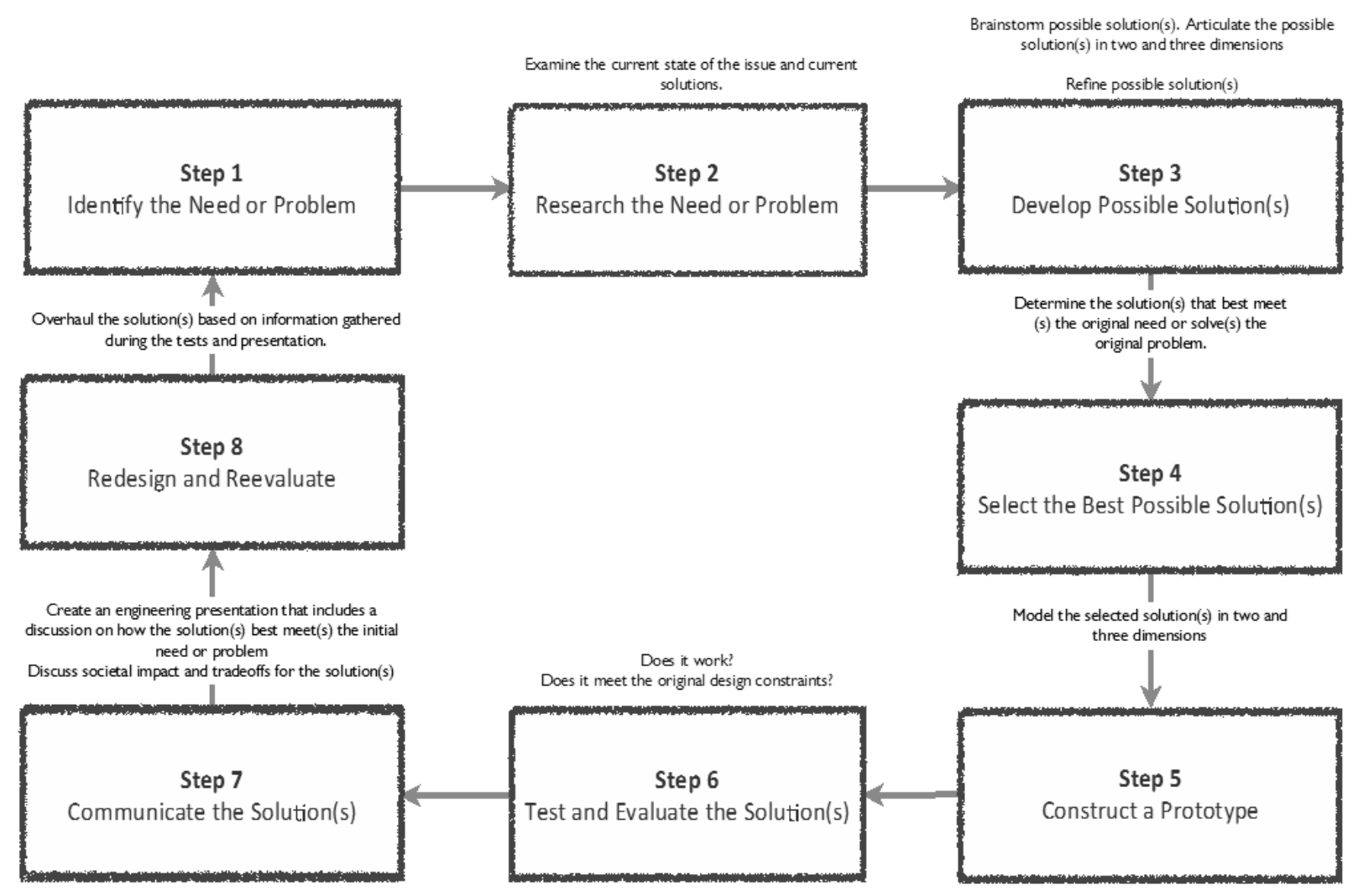

Figure 1: Engineering Design Process

In accordance with engineering standards, Massachusetts is one of the first states to mandate teaching engineering and technology in their school system [10]. Figure 2 defines the state's engineering, science and technology framework to ensure engineering education continuity. The CAPSULE team focuses on two categories to leverage the team's expertise: engineering design and manufacturing technologies (details in Figure 3). Massachusetts state standards are aligned with national standards determined by NETS (National Educational Technology Standards) issued by ISTE (International Society for Technology in Education) allowing the CAPSULE methodology to be scaled-up to the national level. The CAPSULE curriculum is also aligned with STL (Standards for Technological Literacy) issued by ITEA (International Technology Education Association). Given that Massachusetts standards are aligned with national standards, this localized capstone model can be replicated nationally. 


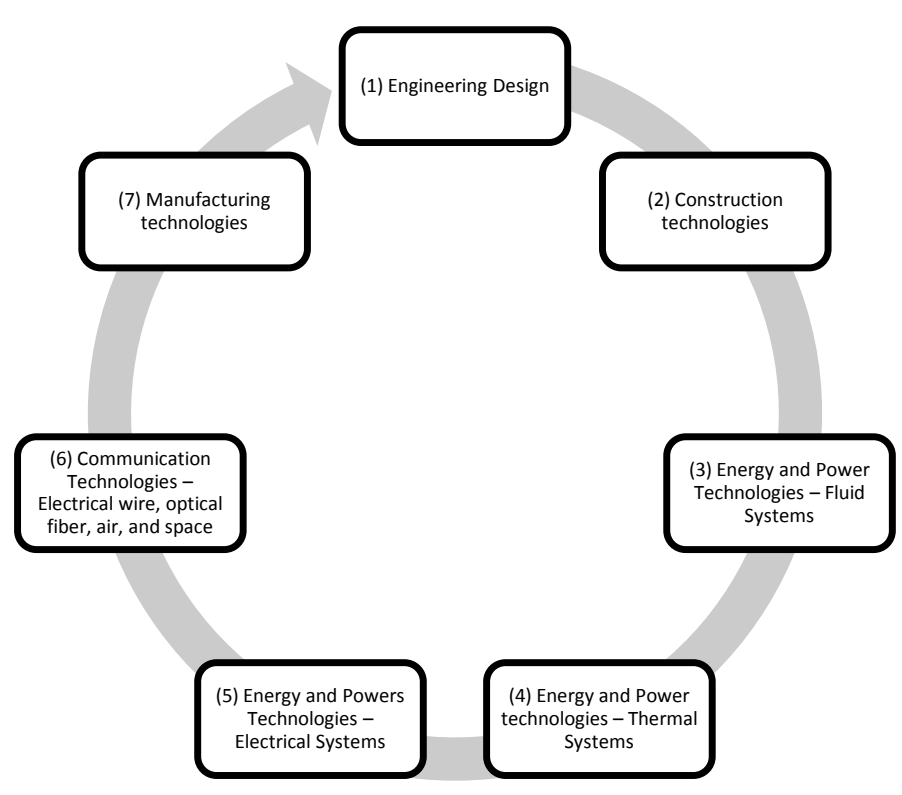

Figure 2: Massachusetts State Engineering/Technology Framework

1. Engineering Design

-Identify and explain the steps of the engineering design process.

- Demonstrate knowledge of pictorial and multi-view drawings.

- Demonstrate the use of drafting techniques using CAD systems.

- Interpret and apply scale to orthographic projections and drawings.

- Interpret diagrams and drawings in the construction of a prototype.

\section{Manufacturing Technologies}

- Describe the basic manufacturing processes - Casting, turning, etc.

- Identify the criteria to select manufacturing processes.

- Describe the advantages of manufacturing automation.

Figure 3: Massachusetts Framework For Engineering Design And Manufacturing Technologies 


\section{CAPSULE PROFESSIONAL DEVELOPMENT AND SUPPORT}

\section{CAPSULE Professional Development}

In order to promote capstone and project based learning, the teachers must fully understand and familiarize themselves with this method of teaching. CAPSULE provides a two-week intensive professional development course where teachers experience group problem solving, prototyping, and open-ended problem solving methods while experiencing similar frustrations that many students feel when they do not understand or cannot comprehend concepts. Through the two weeks, the workshops they attend introduce them to EDP, prototyping, problems solving and a true capstone-like experience. Understanding the EDP process will allow them to implement a capstone-like experience in their classrooms using their subject matter whether that would be physics, chemistry, engineering or geometry. Over the course of the academic year, the CAPSULE program provides two callback sessions as well as support in their classrooms to understand their personal classroom teaching and challenges they face on a day-to-day basis and eventually, how to overcome these challenges.

During the two-week workshop, teachers are exposed to state-of-the-art CAD/CAM (3D Modeling) software as a tool to bring real world objects into the classroom. Table 1 details the agenda of the two-week workshop. Week 1 provides teachers with technological tools to bring into their classroom to introduce theory and application to their students. Week 1 provides pedagogical skills pertaining to understanding and implementation of EDP in product design and provides them with tools to properly implement a capstone-like experience in their classrooms. CAPSULE PD is taught by leveraging the expertise of both the CAPSULE team and outside industry experts. The CAPSULE team was constructed due to the unique teaching methods and previous experiences of its members. The team consisted of expertise in Solidworks ${ }^{\mathrm{TM}}$ modeling, manufacturing, pedagogy, and STEM K12 learning. Similarly, graduate students who experienced both K12 and higher engineering education bridged the K12 and university chasm. Industry experts were introduced to provide context and application of the CAPSULE methodology in the real world.

Week 2 allows participating teachers to design and develop action plans on how they plan to integrate the tools and skills they acquire in Week 1 into their classroom teaching. Teachers are free to select the implementation subject depending on courses taught.

Table 1: CAPSULE Professional Development Course, Summer 2010

\begin{tabular}{|l|l|l|}
\hline Day & Date & Theme \\
\hline Week 1 & Monday July 19 & Capstone Introduced \\
\hline 1 & Tuesday July 20 & $\begin{array}{l}\text { Capstone skills and tools. } \\
\text { Use CAD to conceptualize/design/analyze/prototype }\end{array}$ \\
\hline 2 & Wednesday July 21 & Industry Day: Real world design challenge \\
\hline 3 & Thursday July 22 & STEM capstone projects \\
\hline 4 & Friday July 23 & STEM capstone projects presentations \\
\hline 5 & Monday July 26 \\
\hline Week 2 & \multicolumn{2}{|l|}{} \\
\hline 6 & Tuesday July 27 & Instructional Design \\
\hline 7 & Wednesday July 28 & Resource Exploration \\
\hline 8 & Thursday July 29 & Research and Design \\
\hline 9 & Friday July 30 & Instructional Research and Design \\
\hline 10 & STEM/capstone action plan presentations \\
\hline
\end{tabular}

Through two-weeks, teachers accumulate knowledge to apply to mini projects held throughout the session. The mini projects force teachers to use the technological tools taught to them as well as the methodologies that they have been exposed to. On the Friday of each week, teachers were asked to present and take part in a poster session displaying their methodology, results and discussion (see Figure 4). The focus was on both the possible solutions and how teachers arrived at their respective final solution. 


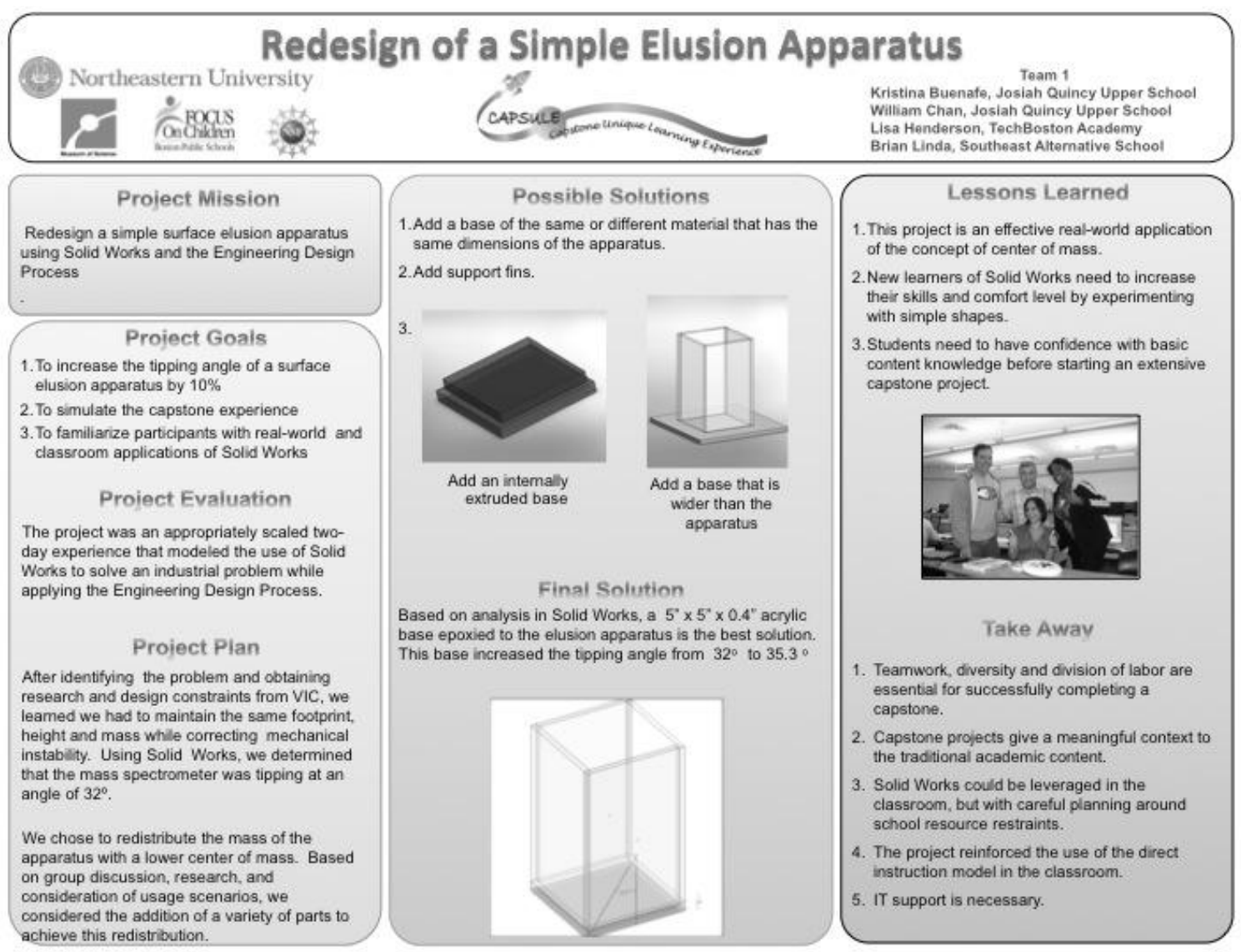

Figure 4: Example Of Group Poster Created For Poster Session

\section{Participants}

Twenty-three participants attended the professional development course. Participants were categorized based on a series of factors such as engineering background, engineering experience, projected teaching, and related STEM subjects. Participants included fourteen males and nine females (See Figure 5).
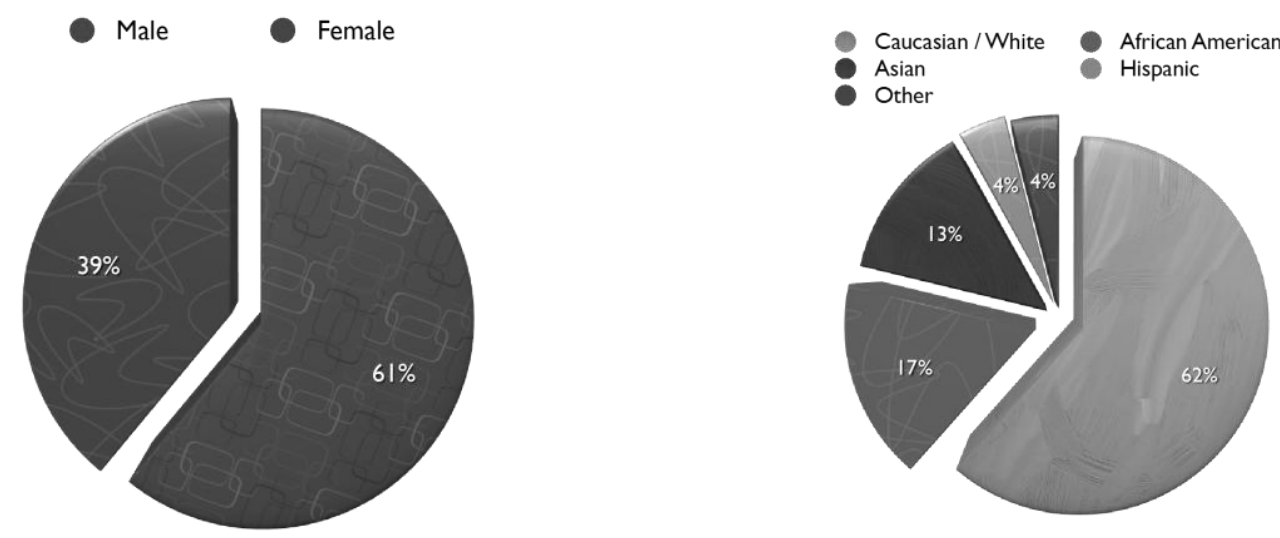

Figure 5: Demographics/Background Of Participants 
Figure 6 shows the diversity of STEM subjects. The goal of CAPSULE was to bring together a variety of STEM subjects to encourage cross disciplines.

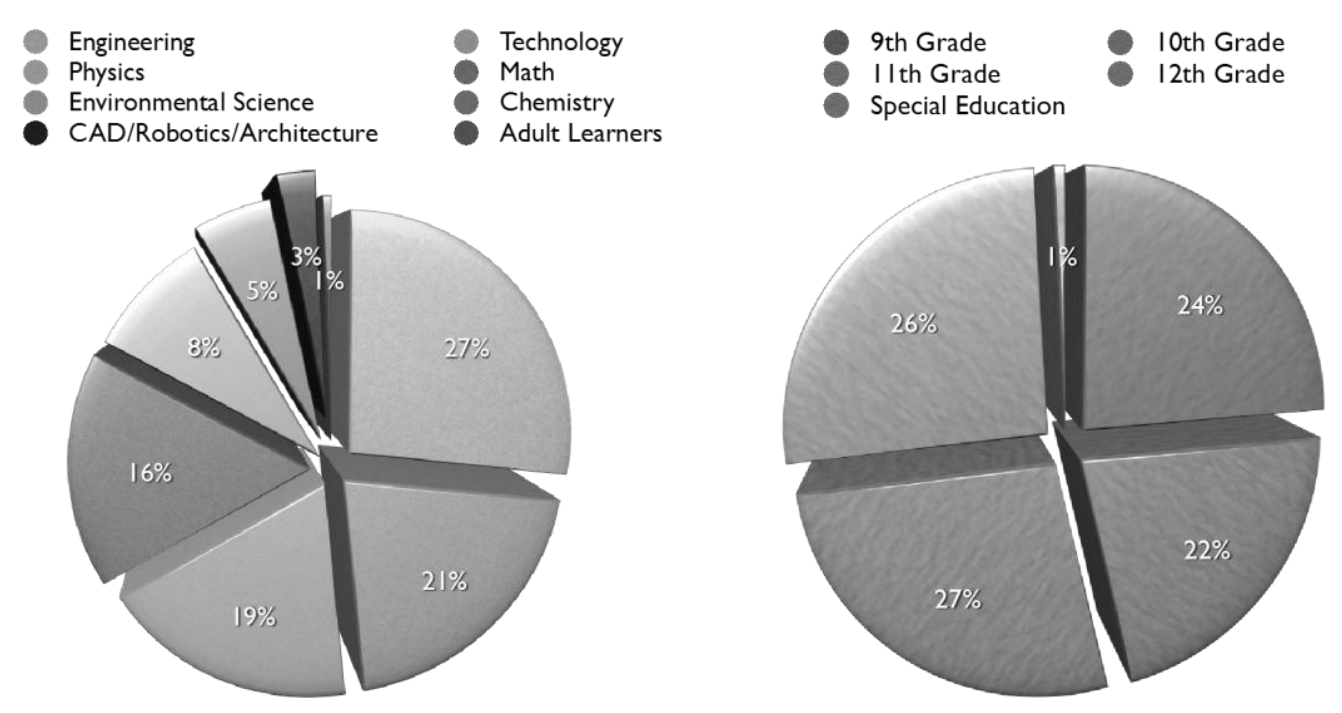

Figure 6: Demographics/Background Of Participants

Teachers can only teach what they know and understand. For teachers to be able to implement the CAPSULE methodology in their classroom, they need to given the proper tools and technology specifically pertaining to engineering and PBL. Participants of CAPSULE must understand and familiarize themselves with provided technology such as Solidworks ${ }^{\mathrm{TM}}$ to translate it effectively to their students. CAPSULE empowers teachers to modify their teaching style to engage students more effectively.

The CAPSULE objective is not to turn teachers into engineers but to expose them to methodologies and tools that they could use in their classrooms. In high school, it is rare for students to ask "What material is that made from?" or "How was this product manufactured?" For teachers to successfully teach EDP, they need to understand how innovation is created using it, the benefits of 3D modeling in a virtual environment and how this understanding will help their students comprehend where new ideas and improvement come from. The fact is, that virtual tools, Solidworks ${ }^{\mathrm{TM}}$, and iterative engineering and refining have saved companies and institutions from wasting time, material, and money. Simulated environments can provide a precise representation of the product and how it would interact in its final setting. For teachers, working on their capstone project in accordance with EDP shows them firsthand a similar experience that their students would face when implementing it in their classrooms. For students, EDP steps will allow them to present problem solutions in the form of virtual models, 3D prototypes, final reports and presentations. Further, EDP is guaranteed to produce multiple solutions to single problems allowing students to appreciate various solutions to the same problem.

\section{RESULTS}

This study utilized pre-post testing, daily surveys and focus groups before and after the course completion. Two mandatory callback sessions as well as pre and post surveys solicited to the classroom students were also implemented throughout the following school year. The PD evaluation entailed two types: formative and summative. A professional development expert from the Boston Public Schools conducted the formative evaluation. This evaluator designed daily evaluation forms for teachers to complete at the end of each day. The purpose of these daily surveys was to allow the CAPSULE team to make any necessary adjustments for the following day. An 
external project evaluator from UMASS Donahue Institute performed the summative evaluation. This evaluator specializes in evaluating the effectiveness of funded STEM projects such as CAPSULE.

The evaluator for the summative evaluation provided an extensive report based on the feedback received. The evaluation instruments include pre and post surveys as well as focus groups. These instruments were all anonymous and did not identify the participants. The pre and post surveys used specialized codes consisting of letters and numbers to match each pre-survey with its corresponding post-survey. The pre-survey was conducted on Monday, Day 1 and the post-survey was conducted on Friday, Day 10. The survey questions were designed to measure the knowledge gained by the teachers specific to EDP, CAD, the capstone experience and manufacturing.

The focus group evaluation was conducted during a two-hour meeting between the evaluator and randomly selected group of 10 out of 23 teachers on the Friday, Day 10. The purpose of the focus group was to acquire a broader perspective of the PD not typically captured via surveys.

There were two follow-up callback sessions, one in January 2011 and the final one at the end of April 2011. The purpose of the callback sessions were to become reacquainted with the teachers, continue to build a community, and see the progress and setbacks of the school year.

\section{DISCUSSION}

\section{Analysis}

The two-week workshop provided teachers with the student-like experience again. Teachers were engaged in design challenges before and after learning the process of EDP. Teachers experienced what their students would experience and how it could enhance their classroom teaching and activities. Many teachers went through the frustration of not grasping Solidworks (CAD/CAM) very easily and working in teams, collaborating with new colleagues. To assist teachers, innovative engineering based approaches are leveraged through mini design challenges. Referring to the first day of teachers' PD, teachers were asked to form groups and design a 3-legged design chair that was safe, stable, and could carry a minimum weight. Teachers were divided into teams of three. Teachers brainstormed multiple designs, created miniature prototypes and then life-size models. They were asked to reflect on the experience and process and what how they perceived the engineering design process methodology. Similar design challenges throughout the week proved useful in culminating to the final design challenge at the end of week 1. Teachers were asked (see Figure 7) to design a 3-legged chair before understanding or knowing the principles behind the exercise.

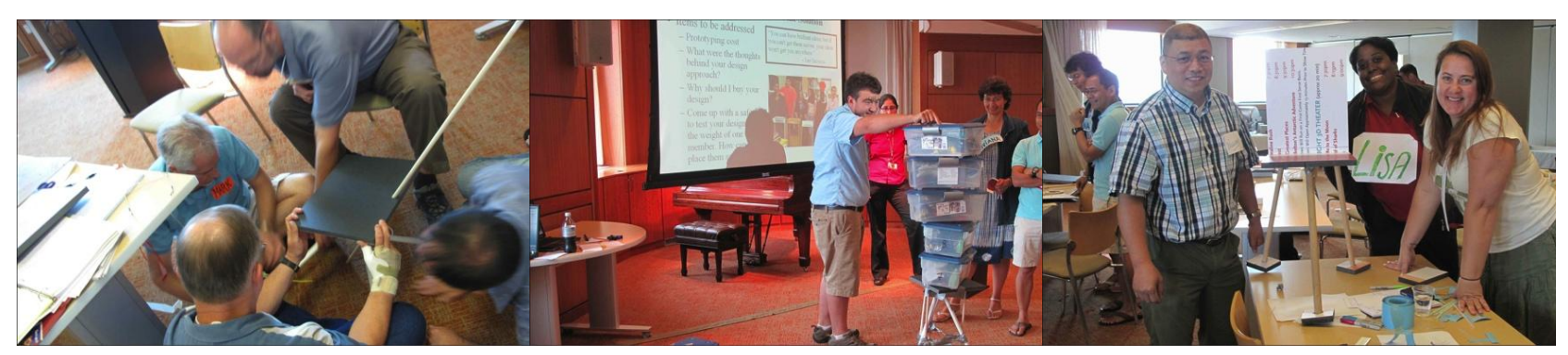

Figure 7: Design Of 3-Legged Chair

They also experience a simple but industry related problem using Solidworks and presenting each solution during a poster session. Many teachers were surprised at the number of solutions produced to such a simple problem. Figure 8 displays teachers learning and working with the 3D modeling software Solidworks, discussing problems and solutions with an instructor, and concluding Week 1 with a poster session, very comparable to the collegiate capstone courses. 


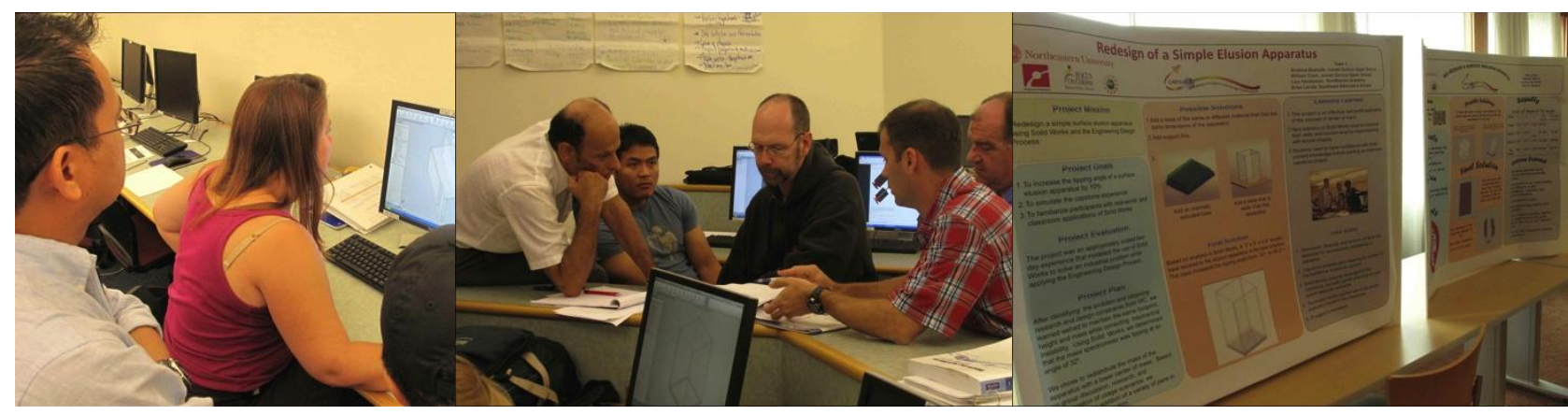

Figure 8: Redesign Of Elusion Apparatus (Problem Changing Weight Distribution Of A Box) And Poster Session

The value of real-world relationships in engineering is, for many people still very theoretical. In order to showcase the significance of real-world relationships, two pedagogical techniques were utilized to emphasize this point with participants. The most accurate method to display this is through industry experts. On Day 3 of the program, individuals from industry were invited to share their experiences with solving real-world solutions. On Day 4 and 5 , teachers were introduced to a simplified industry project and have them create and modify possible solutions. Teachers use all the tools and resources learned in the previous three days for this final week 1 project. In summer 2010, the capstone project was to redesign a Surface Elusion Apparatus (see Figure 9). The company was trying to determine how to lower its center of mass to reduce the tipping probability by at least $25 \%$. Similar to any problem, the industry problem had constrains such as maintaining the same mass and overall dimensions (length, width, and height). The goal was to have groups think about how they would redistribute the mass so it was more bottom heavy [10].
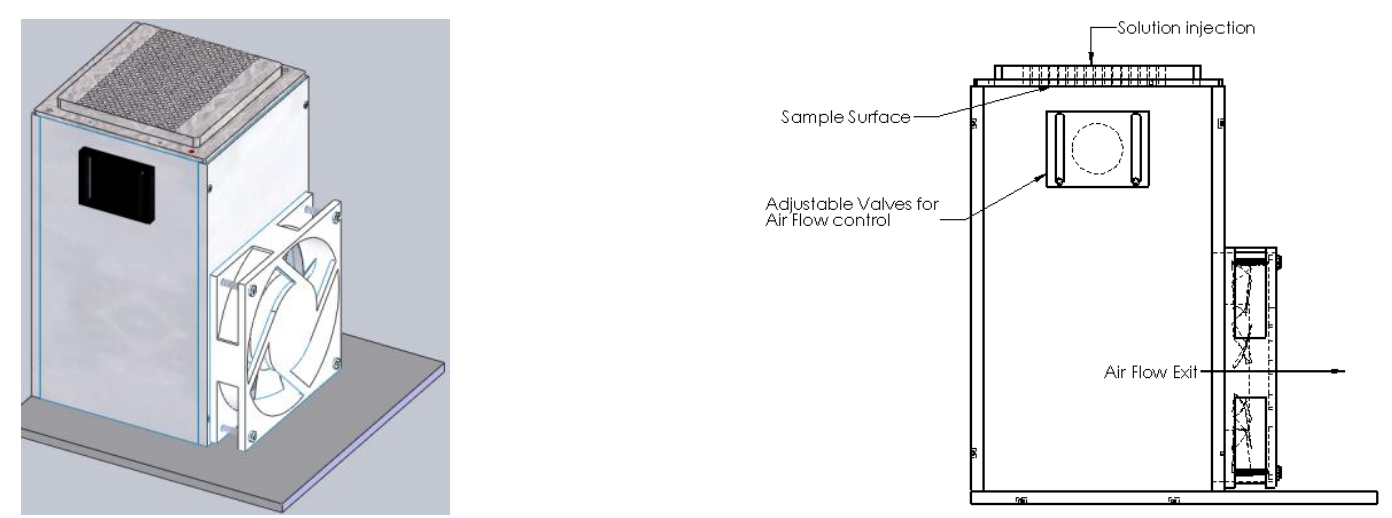

Figure 9: Sample Surface Elusion Apparatus

This industry problem forced teachers to use a CAD system to construct a model, determine its mass property calculations and to find the model's center of mass. This allowed them to compare their findings with the original part to establish if their design would meet the criteria. Figure 10 demonstrates two examples of teacher solutions. Using EDP, all groups would brainstorm possible designs on paper and then create their final solution in CAD [10]. 

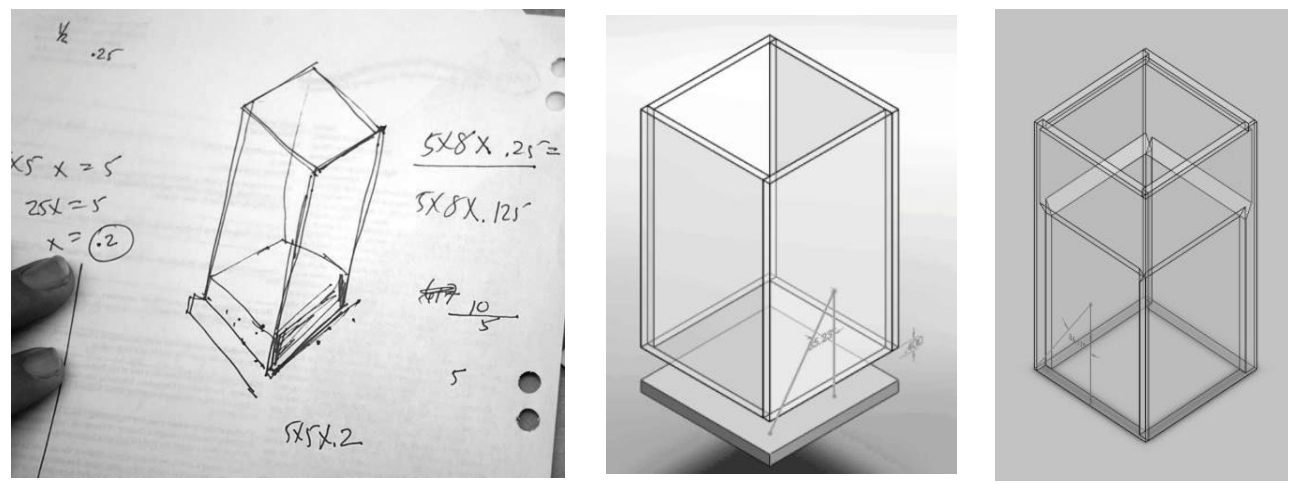

Figure 10: Brainstorming And Final CAD Solutions

Week 2 built upon week 1. During Week 2, teachers collaborated with instructors and colleagues to devise how they could implement more capstone based learning in their classrooms. Week 2 challenges them to think critically of how to use what they have learned and improve their teaching, their delivery method, and their content. Using the skills and tools learned in week 1, the teachers are then asked to envision doing capstone-like experiences in their own classroom. This week was enhanced with more industry individuals, a visit to Boston's Museum of Science and other workshops to teach and provide teachers resources to use in their own classrooms. This week focused on the research and development of mini-projects, culminating projects and provided time to converse with colleagues to discuss what teachers in the same subjects and others are implementing in their upcoming school year. Figure 11 reports the benefits of the two-week PD course.

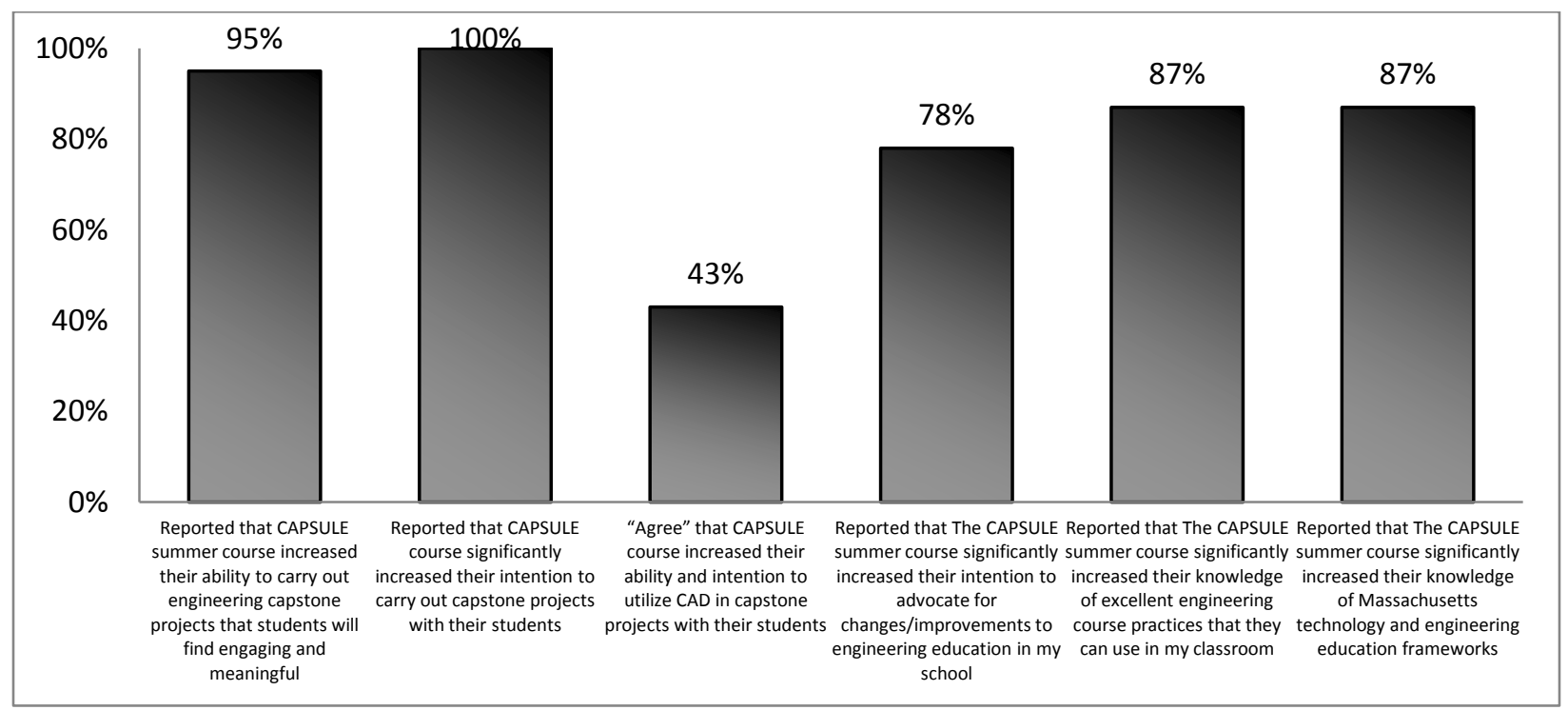

Figure 11: Summative Results, Benefits Of Summer Professional Development

\section{Follow-Up Callback Session}

On January 28, 2011, the CAPSULE team held the first callback session to see the results of the professional development course and what methods had transferred to the classroom. One teacher introduced stopanimation (SAM) videos for her pre-calculus class. One concept her students repeatedly had issues remembering was the Pythagorean theorem, $a^{2}+b^{2}=c^{2}$ [11]. This student created a SAM animation video of a tank trying to cross a gap. For his tank to cross the gap, he needed to build a bridge. He used the Pythagorean theorem to measure 
the correct distance of the bridge. Figure 12 displays screenshots of this student's video. This student provided the teacher with this feedback: "This project was one of the best projects I ever had but it was also one of the hardest. It was really fun making the video but to make it took a lot of time. Creative math projects are harder then they seem at first I thought I was just going to wing it and draw some stuff. But it needed a lot of planning and preparations."
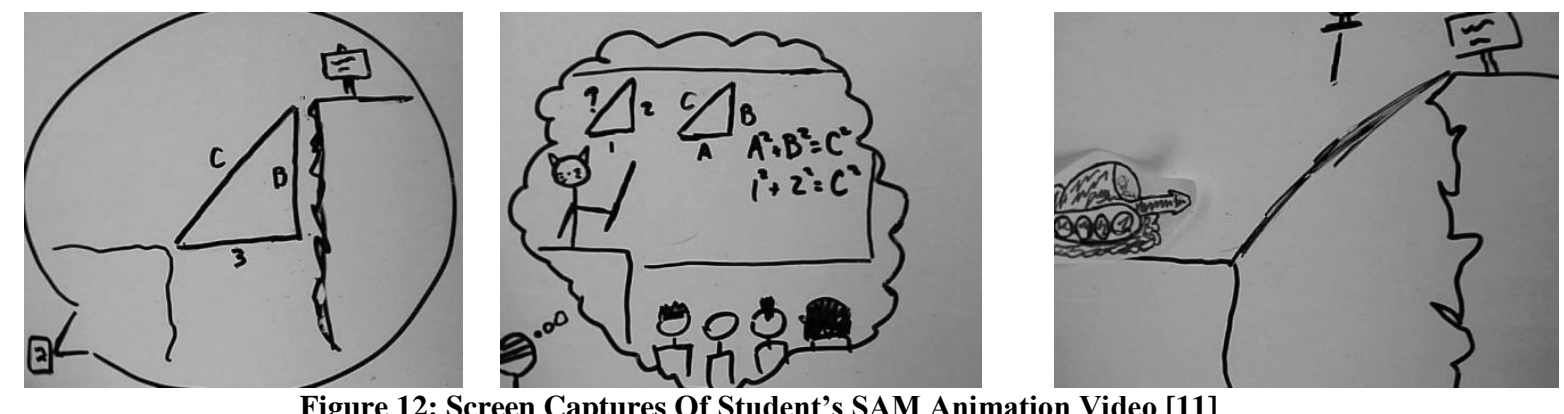

Figure 12: Screen Captures Of Student's SAM Animation Video [11]

Boston's Museum of Science has a published book that is utilized in many classrooms titled Engineering the Future. It provides potential projects for teachers, examples, instructions and resources pertaining to STEM course subjects. Another teacher used some of these projects to teach his Engineering Technology course. Unlike typical STEM subjects like chemistry or geometry, his course is entirely project-based using machines like laser cutters and 3D printers. Figure 13 displays a two examples of projects held during the first semester.
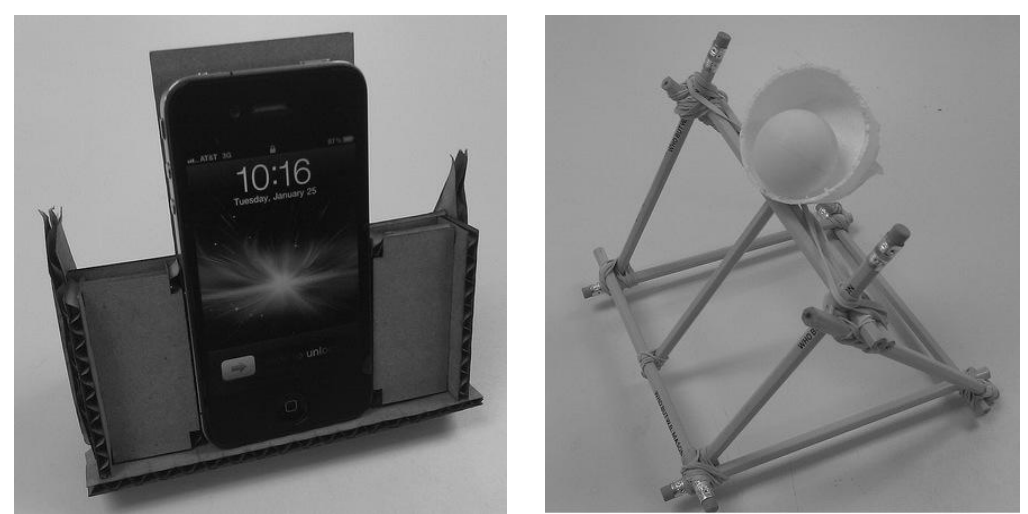

Figure 13: Cardboard Cellphone Holder And Pencil Based Ping Pong Ball Catapult

This teacher used the EDP methodology to create projects in a logical manner helping students understand the purpose of each stage. He then taught students 3D modeling to express their ideas and finished up refining and prototyping. This teacher discovered he had a wide range of abilities and motivation. Surprisingly, those that typically were not engaged or involved in class suddenly thrived in this project based environment

Other teachers implemented more complex projects such as the mousetrap car. One teacher specifically set his students up to fail very early in the design process. He believed that failing early was key because it forced them very quickly to focus on what went wrong, to reevaluate it and redesign a better solution. His emphasis was on project iteration, understanding that this practice was very common in both higher-level education and in industry. He presented the problem, the goal and the constraints to his students for each project (see Figure 14). 


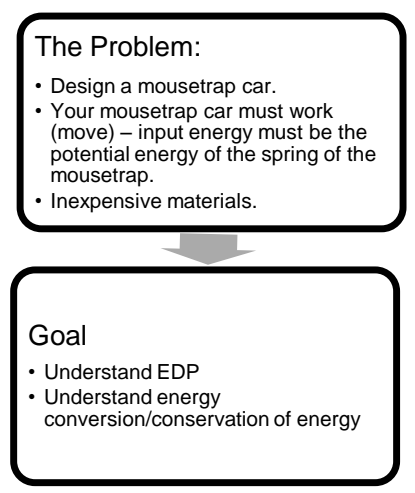

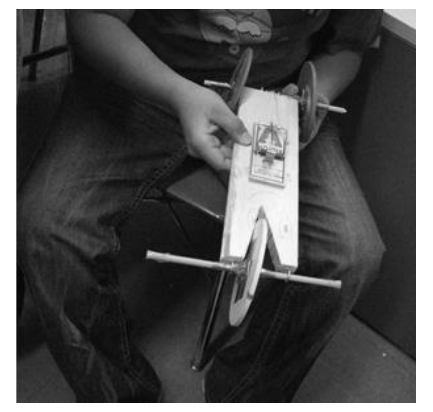

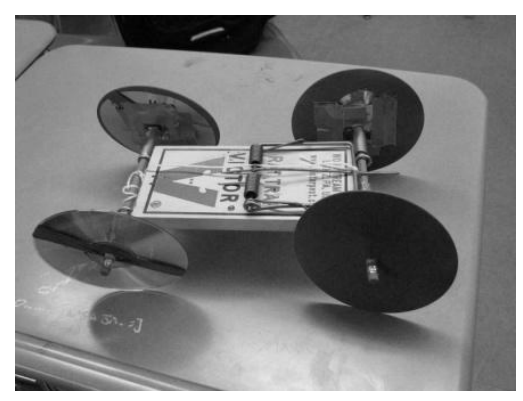

Figure 14: Mousetrap Car Project

With the variety of subjects, some teachers chose to implement mini projects while others focused on culminating projects. Some teachers found with their students, it was better to implement a short-term project that allowed them to immediately apply the principles they learned to an application. Either way, the tools learned in CAPSULE appear to be beneficial to the respective students. Teachers are discovering new ways to teach and reinforce their subject matter. With such a diverse group of teachers and subject matter, it was interesting to discover that many tribulations that occurred throughout the school year were collectively very similar. Many teachers experienced a change in students' abilities and ambition when they modified lesson plans using projectbased learning rather than lecture-style.

There were also unexpected financial and physical challenges that appeared during implementation. At the collegiate level, budgets are carefully monitored but they exist. At the high school level, especially in urban school districts, budgets for project implementation are nearly non-existent. At the university level, constraints are experienced but not to the extent of high schools. The challenge for the coming year is to design projects that can be implemented with the resources available at the high school level. In the case of winter 2010-2011, the northeast had an unexpected number of snow days (15+), which caused significant disruption in all schools.

Student performance, achievement and motivation are the utmost concern when trying to impact the classroom. Ultimately, it is all about the effect on the students. Teachers were asked during an informal setting to reflect on the past 6 months and express how CAPSULE has affected their classroom regardless of the outcome. Here are a few excerpts [12]:

- $\quad$ CAPSULE program has helped to refocus their energy.

- We have modified students learning to more project-based and presentation dependent activities

- $\quad$ Focus on group collaboration and group problem solving

- $\quad$ Constantly relate theory to practice and their own environment

- $\quad$ Understand the theory behind concepts and how it relates to their students life.

- Incorporate projects due to equipment stipend. Was able to purchase electronic equipment to build solar ovens.

- $\quad$ Students were intrigued when introduced to more application based math rather than theory. My students realized math has real world applications.

- $\quad$ The CAPSULE PD was one of the best PDs I have had. The idea development, networking and support have all been so valuable!

- $\quad$ Science fair projects were completed at a significantly higher level than previous years.

- $\quad$ Students focused on the problem rather than just the build.

- Students used EDP as a systematic brainstorming tool to design and develop a solution.

- $\quad$ Students concentrated on a structured approach to testing and reporting rather than just completing the project. 


\section{FUTURE RESEARCH AND LESSONS LEARNED}

There has been valuable insight gained from the first-year implementation of CAPSULE. There are significantly more constraints at the high school level and the limited resources available to them. The challenges that teachers faced this past year will contribute substantially to modifications for the second year. Some of the changes that will occur are:

- $\quad$ Clarify and explain the capstone experience earlier in the workshop

- $\quad$ Redesign the CAD instruction on how to teach teachers SolidWorks ${ }^{\mathrm{TM}}$ software

- $\quad$ Redesign and rethink about the industry project (or multiple projects)

- Make it more relevant to teachers' respective subjects (i.e. make a chemistry project, a math project, etc.)

- $\quad$ Redesign and rethink about the industry project (or multiple projects)

- $\quad$ Redesign the pre and post surveys to correctly gauge the true knowledge of teachers and knowledge gained at the end of the PD

- $\quad$ Introduce more collegiate capstone experience examples from past university students

For the second year implementation of this study, the CAPSULE team received nearly 100 applicants for 30 participant slots. There are participants traveling from Connecticut, North Carolina, and Florida this year.

\section{CONCLUSION}

Preliminary results indicate that teachers have started to implement various skills learned during CAPSULE in their classrooms and have begun small capstone design projects pertaining to their subject matter. Their feedback has resulted in value added learning in their STEM courses. As teachers have indicated through multiple evaluation methods, the tools and methodologies that are provided through CAPSULE appear valuable and beneficial to their students. Understanding the capstone experience and capstone-design projects through hands-on, project-based learning can greatly enhance the absorption and interest of their students. As indicated in the midyear evaluations, over half of the participants had implemented capstone-like experiences in their courses, ranging from AP physics to AP biology to geometry. A significant number of teachers are using the three-legged chair project in their classrooms. Their evaluations and critiques have provided priceless feedback that will be incorporated into year 2 .

Alumni of CAPSULE 2010 have also been welcomed back to year 2 of CAPSULE PD to share their hardships of the past school year to build a community of CAPSULE graduates and to prevent similar issues in the future. There are many improvements to CAPSULE 2011 due to lessons learned in 2010.

\section{ACKNOWLEDGEMENT}

This work is supported by the National Science Foundation under grant numbers DRL 0833636. Any opinions, findings, and conclusions or recommendations expressed in this material are those of the author(s) and do not necessarily reflect the views of the National Science Foundation.

\section{AUTHOR INFORMATION}

Jessica Chin is a Ph.D. Candidate in the Department of Mechanical and Industrial Engineering at Northeastern University. Her research focuses on the implementation of engineering design processes using traditional and virtual methods. Her Ph.D. focus is on three-dimensional imaging to quantify the progression of wounds and wound healing. Additional research includes the implementation of capstone experiences at the high school level through Northeastern University's CAPSULE program. She received her B.S. in Mechanical and Biomedical Engineering from Rensselaer Polytechnic Institute and her M.S. in Technological Entrepreneurship from Northeastern University. E-mail: chin.jes@husky.neu.edu 
Abe Zeid is a Professor with the Department of Mechanical and Industrial Engineering at Northeastern University. His research topics include the use of mobile agents to facilitate information access in manufacturing environments, developing XML-based algorithms for mass customization, and developing a Java-based and Web-based system for disassembly analysis. The system allows users to disassemble the components of a PC, and calculate the disassembly cost associated with each component. Dr. Zeid has written textbooks in the areas of CAD/CAM and the Internet/World Wide Web. He is an ASME Fellow. E-mail: zeid@coe.neu.edu

Claire Duggan is currently the Director for Programs and Operations for The Center for STEM Education at Northeastern University. She also serves as Director for K-12 outreach for the Gordon Center for Subsurface Sensing and Imaging and the Department of Homeland Security Center for Excellence, ALERT. She oversees the development and implementation of a number of student and teacher programs including the Exxon Mobil Summer Science Camp, the Young Scholars and Research Experience for Teachers programs. She works with faculty from across the campus in the development and implementation of new programs models designed to address challenges in STEM education nationwide. E-mail: c.duggan@ neu.edu

Sagar Kamarthi is an Associate Professor of Industrial Engineering at the Northeastern University, Boston, MA. $\mathrm{He}$ received his MS and PhD degrees from the Pennsylvania State University. He teaches courses in manufacturing, mass customization, and machine learning. His research interests are in product, process, and system monitoring and diagnostics, modeling analysis of manufacturing and service systems, and nanomanufacturing. His research yielded over 100 peer-reviewed publications, received multiple best paper awards, and received several grants from awards from NSF. E-mail: sagar@coe.neu.edu

\section{REFERENCES}

1. Huffman, D., et al., Collaborative evaluation communities in urban schools: A model of evaluation capacity building for STEM education. New Directions for Evaluation, 2006. 109: p. 73.

2. $\quad$ Bybee, R., What Is STEM Education? Science, 2010. 329(5995): p. 996.

3. Locke, E., Proposed Model for a Streamlined, Cohesive, and Optimized K-12 STEM Curriculum with a Focus on Engineering. 47 Pedagogical Content Knowledge and Industrial Design Education, 2009: p. 23.

4. Atkinson, R., et al., Addressing the STEM Challenge by Expanding Specialty Math and Science High Schools. Information Technology and Innovation Foundation, 2007: p. 13.

5. Laird, J., M. Alt, and J. Wu, STEM Coursetaking among High School Graduates, 1990-2005. MPR Research Brief. Online Submission, 2009: p. 20.

6. National Research Council, Building a workforce for the information economy2001: National Academies Press.

7. Savery, J., Overview of problem-based learning: Definitions and distinctions. The Interdisciplinary Journal of Problem-Based Learning, 2006. 1(1): p. 9-20.

8. Dym, C.L., et al. Engineering design thinking, teaching, and learning. 2005. Citeseer.

9. Massachusetts Department of Education, Massachusetts Science and Technology/Engineering Curriculum Framework, D.o. Education, Editor 2006, Massachusetts Department of Education: Malden. p. 156.

10. Zeid, A., et al., Implementing the Capstone Experience Concept for Teacher Professional Development, in 118th ASEE Annual Conference \& Exposition2011: Vancouver, B.C. CANADA.

11. Tufts University, C.f.E.E.a.O. SAM Animation: Putting Students' Ideas in Motion. 2011 [cited 2011 February 5]; Available from: http://www.samanimation.com/.

12. Chin, J., et al., Reenergizing and Reengaging Student Interest through CAPSULE, in ISEC 2011 : Integrated STEM Education Conference2011, IEEE Xplore: Ewing, NJ. p. 5. 